\title{
PERENCANAAN PRODUKSI AGREGAT CV XYZ DENGAN JUMLAH TENAGA KERJA TETAP
}

\author{
AGGREGATE PRODUCTION PLANNING CV XYZ WITH AMOUNT OF PERMANENT EMPLOYMENT
}

\section{Fadhillah Fairuzzahira*)1, Sukardi ${ }^{* *}$, dan Yandra Arkeman ${ }^{* *}$}

\author{
*) Sekolah Bisnis, IPB University \\ Jl. Raya Padjajaran, Bogor 16151, Indonesia \\ ${ }^{* *}$ Departemen Teknik Industri Pertanian, Fakultas Teknologi Pertanian, IPB University \\ Jl. Dramaga, Kampus IPB Dramaga Bogor 16168, Indonesia
}

\begin{abstract}
C V X Y Z$ is a growing plywood company. In increasing the company's competitiveness, $C V X Y Z$ seeks to find more ideal production planning for the company. The difference between supply and demand of CVXYZ has a total gap of 7,676 m3 over a period of 30 months. This proves that the current $C V X Y Z$ production planning is not ideal to be able to keep up with fluctuating demand. This study aims to analyze medium term production planning. Demand forecasting method is used to determine demand in the coming 12 months period. To compare the current CVXYZ strategy with the level, chase, mixed strategy. Based on calculations that have been made using demand and CV XYZ production variables, it is known that the ideal method used for future production planning is the chase strategy. The chase strategy focuses on eliminating existing inventory in the company, using adjusting the number of working days to the number of demands, as well as purchasing units from subcontracts. The use of a chase strategy has a 43\% lower cost impact. In 2017-2018, the average monthly production cost is Rp1,633,316,531 to Rp930,905,200.
\end{abstract}

Keywords: demand forecasting, aggregate planning, level strategy, chase strategy, mixed strategy

\begin{abstract}
Abstrak: CV XYZ merupakan perusahaan industri kayu lapis (plywood) yang sedang berkembang. Dalam meningkatkan daya saing perusahaan, CV XYZ berupaya mencari perencanaan produksi yang lebih ideal untuk perusahaan. Perbedaan antara persediaan dan permintaan CV XYZ memiliki kesenjangan total sebanyak $7.676 \mathrm{~m} 3$ dalam kurun waktu 30 bulan. Hal tersebut membuktikan bahwa perencanaan produksi CV XYZ saat ini belum ideal untuk dapat mengikuti jumlah permintaan yang berfluktuasi. Penelitian ini bertujuan untuk menganalisis perencanaan produksi jangka waktu menengah. Peramalan permintaan dilakukan untuk mengetahui jumlah permintaan pada periode 12 bulan mendatang. Selanjutnya, membandingkan strategi CV XYZ saat ini dengan strategi level, chase, mixed. Berdasarkan perhitungan yang telah dilakukan menggunakan permintaan yang telah diramalkan dan variabel produksi CV XYZ, diketahui bahwa metode ideal yang digunakan untuk perencanaan produksi kedepaan adalah strategi chase. Strategi chase berfokus untuk meniadakan persediaan yang ada di perusahaan, menggunakan penyesuaian jumlah hari kerja dengan jumlah permintaan, serta melakukan pembelian unit dari subkontrak. Penggunaan strategi chase memiliki dampak penurunan biaya sebesar 43\%. Pada tahun 2017-2018 ratarata biaya produksi perbulan senilai Rp1.633.316.531 menjadi Rp930.905.200.
\end{abstract}

Kata kunci: peramalan permintaan, perencanaan agregat, strategi level, strategi chase, strategi mixed

\footnotetext{
${ }^{1}$ Corresponding author:

Email: fadhila.28@gmail
} 


\section{PENDAHULUAN}

Seiring dengan meningkatnya kebutuhan bahan konstruksi keberadaan industri pengolah kayu mulai berkembang khususnya untuk produk plywood. Plywood (kayu lapis) merupakan panel kayu yang tersusun dari lapisan veneer (lembar kayu) dibagian luarnya, sedangkan dibagian core (inti) bisa berupa veneer atau material lain, diikat dengan lem kemudian di-press sedemikian rupa sehingga menjadi panel yang kuat. Plywood merupakan salah satu dari 10 komoditi utama ekspor Indonesia yang masuk ke dalam kategori produk hasil hutan (Kemenpri, 2017). Produk plywood di dukung oleh bahan baku yang mempunyai potensi besar dalam ketersediaannya yaitu pohon sengon (Paraserianthesfalcataria) yang merupakan spesies asli dari Indonesia. Selama ini, kayu sengon dari Indonesia dikenal memiliki kualitas terbaik dibandingkan negara lainnya seperti Malaysia dan Filipina. Pohon sengon merupakan salah satu pionir pohon multipurpose tree species di Indonesia dan menjadi bahan baku yang sangat baik untuk industri kayu karena kecepatan tumbuh serta dapat hidup di berbagai kondisi tanah.

Jumlah ekspor rata-rata produk plywood dalam 5 tahun pada tahun 2010 hingga 2015 mencapai 2 juta ton per tahun. Pada tahun 2017, ekspor produk kayu olahan Indonesia ke USA menunjukkan tren positif. Berdasarkan data shipment dokumen $\mathrm{V}$ legal, nilai ekspor pada tahun 2017 mencapai US\$264 juta atau naik 10\% dibandingkan dengan 2016. Dengan tingkat volume ekspor tersebut Indonesia dapat digolongkan memiliki peranan dominan dalam pasar plywood dunia yang telah berkontribusi sebanyak $14.1 \%$ dari total ekspor plywood dunia, menjadikan Indonesia sebagai negara pengekspor plywood terbesar ke-2 setelah China (Tridge, 2016). Kurang lebih $80 \%$ produksi plywood Indonesia selama ini dijual untuk tujuan ekspor ke berbagai negara seperti Tiongkok, Jepang, AS, Koreaselatan, dan Arab Saudi (BPS, 2018).

Industri pengolahan kayu di Indonesia merupakan salah satu barometer peningkatan perekonomian nasional dan memegang peranan penting dalam upaya meningkatkan penerimaan negara dari sektor kehutanan. Tercatat pada tahun 2014 industri plywood di Indonesia berjumlah 161 perusahaan dan terdapat peningkatan tiap tahunnya yaitu sebesar 8-12\%, hingga tahun 2018 jumlah industri sebanyak 256 perusahaan eksportir plywood di Indonesia (Kemenperin, 2018). Persaingan juga berasal dari perusahaan asing sebagai bagian dari masyarakat ekonomi asean (MEA) yang dengan mudah memperjual-belikan hasil produksi (Longdong, 2016). Perkembangan industri perkayuan yang demikian pesat mendorong para industri manufaktur dalammemberikan harga terbaik pada konsumen. Harga pasar plywood sangat dipengaruhi oleh perilaku konsumen, jika daya konsumtif turun maka dapat terjadi penurunan harga pasar plywood dan begitupun sebaliknya (Susanto et al. 2017). Sebagai perusahaan yang bersaing, CV $\mathrm{XYZ}$ diharapkan bisa menetapkan harga yang mampu mengikuti keadaan pasar produk plywood.

Saat ini, sebagian besar perusahaan manufaktur berusaha untuk mendapatkan laba dan peningkatan yang lebih besar untuk mendapatkan keunggulan kompetitif terhadap yang lain. Keuntungan tersebut dapat dicapai dengan menghasilkan lebih banyak pendapatan atau mengurangi biaya produksi (Fajar dan Lestari, 2017). CV XYZ merupakan salah satu manufaktur plywood yang dibangun pada tahun 2014 dan beroperasi secara stabil pada tahun 2017. CV XYZ selalu berupaya menemukan perencanaan produksi yang lebih baik untuk meningkatkan daya saing perusahaan. Salah satu upaya yang sedang dilakukan saat ini adalah mencari model perencanaan produksi yang sesuai dengan perusahaan dan berdampak biaya minimum. Pada Gambar 1 dapat dilihat bahwa jumlah persediaan selalu berada di atas jumlah permintaan yang mengakibatkan jumlah persediaan plywood yang terdapat di gudang menjadi tinggi. Jika hal ini berlanjut, cashflow perusahaan menjadi terhambat. Modal untuk pembelian bahan baku teralihkan pada persediaan. Ketersediaan bahan baku terancam akan akibat ketidaksanggupan perusahaan dalam pembelian secara kontan sehingga supplier lebih memilih menjual bahan baku tersebut ke perusahaan lain.

Pemahaman tentang isu-isu strategis, taktis, dan operasional terkait hubungan antara pasar, produk, dan produksi merupakan hal mendasar (Olhager dan Wikner, 2000). Perusahaan harus memiliki strategi untuk memenangkan persaingan. Salah satunya dengan menentukan perencanaan yang tepat, agar produksi dapat memenuhi permintaan sekaligus menghindari terjadinya penumpukan persediaan di gudang (Wardhani, 2010). Persediaan timbul karena adanya ketidakpastian akan jumlah yang dibutuhkan, dan ketidaktepatan waktu. Oleh karena itu, kuantitas dan waktu produksi yang tepat akan mampu meminimalkan jumlah persediaan (Sobandi dan Kosasih, 2014). perencana tersebut digunakan untuk dapat mencegah 
fluktuasi permintaan, yang secara langsung bertanggung jawab atas kelebihan atau kekurangan sumber daya yang tersedia di organisasi (Filho et al. 2010).

Dalam situasi dengan kompleksitas yang terus meningkat, semakin penting untuk memahami produksi dan bereaksi segera terhadap perubahan permintaan atau pasar dengan benar (Gansterer, 2015). Perusahaan saat ini belum menerapkan sebuah metode peramalan formal untuk memprediksi permintaan yang akan datang. CV XYZ menentukan jumlah produksi berdasarkan permintaan dari kepala perusahaan yang menginginkan produksi pada tingkat tertentu. Ketika produksi telah memiliki perencanaan jumlah jam dan tenaga kerja untuk mengatasi fluktuasi permintaan, produksi dapat berjalan tepat waktu, dan jumlah permintaan dapat dipenuhi (Noegraheni dan Nuraldi, 2016).

Kegiatan produksi yang efektif dan efisien diperlukan untuk menjamin ketersediaan produk untuk pemenuhan kebutuhan pelanggan sehingga pelaksanaan operasional perusahaan tidak mengalami masalah terkait perencanaan produksi yang sudah dibuat dan jumlah permintaan (Ramadhani et al. 2012). Dalam mewujudkan suatu perencanaan produksi yang efektif dan efisien dibutuhkan perhatian lebih terhadap faktor-faktor penunjang seperti jumlah penggunaan tenaga kerja, kapasitas produksi, waktu siklus dan penjadwalan shift kerja. Hal tersebut untuk dapat mengantisipasi terjadinya ketidakpastian jumlah permintaan yang membuat banyak tenaga kerja dalam keadaan menganggur atau sebaliknya, ketidakcukupan tenaga kerja sehingga menghambat waktu produksi.

Perencanaan produksi yang baik dapat menjadikan pemakaian bahan baku lebih baik sehingga kondisi persediaan bahan baku pun terkontrol dan tidak berlebih. (Susanti et al. 2015). Dengan melakukan aggregate planning, perusahaan dapat dengan baik melakukan penentuan terhadap jumlah sumber daya yang digunakan untuk menekan biaya yang akan dikeluarkan (Amri et al. 2012). Perencanaan produksi merupakan bagian dari rencana strategi perusahaan dan dibuat secara harmonis dengan rencana bisnis dan rencana pemasaran (Purnomo, 2010). Penelitian ini bertujuan untuk menganalisis perencanaan produksi yang ada di CV XYZ dan memberikan usulan perencanaan produksi jangka menengah untuk 12 bulan kedepan. Tujuan nya untuk mendapatkan biaya produksi minimum dan competitive advantage pada periode mendatang. Data yang diperoleh dari perusahaan digunakan sebagai input dalam peramalan permintaan dan perencanaan produksi agregat.

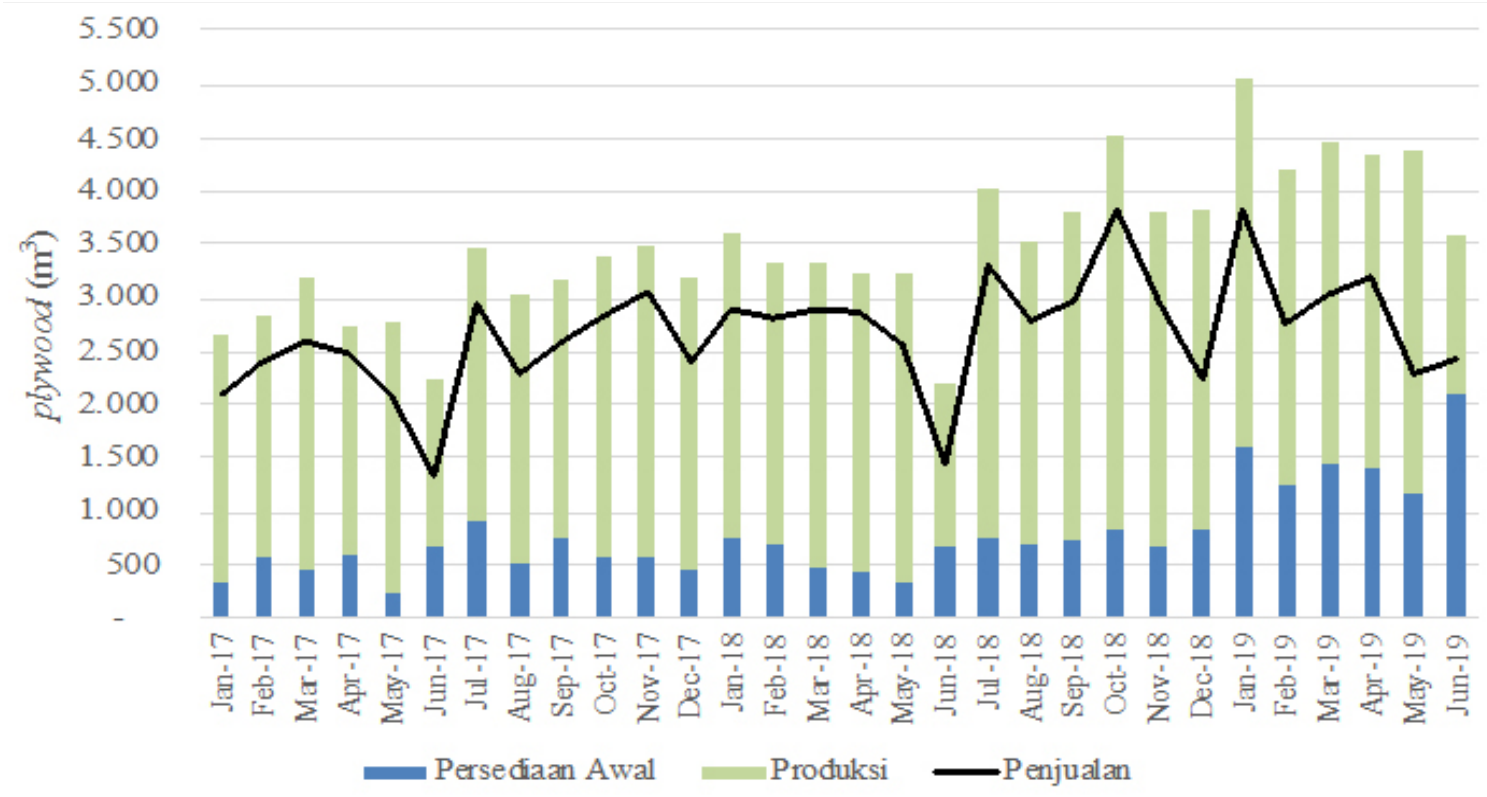

Gambar 1. Jumlah persediaan awal, produksi dan penjualan CV XYZ 


\section{METODE PENELITIAN}

Penelitian dilaksanakan pada CV XYZ yang berlokasi di wilayahKecamatanPringsurat, KabupatenTemanggung, Jawa Tengah. Lokasi penelitian dipilih secara sengaja dengan pertimbangan CV XYZ merupakan salah satu produsen plywood yang sedang berkembang dan memerlukan perencanaan produksi yang baik untuk meningkatkan daya saingnya. Kegiatan pengumpulan data dilaksanakan pada bulan April-Juni 2019. Jenis data yang digunakan dalam penelitian ini adalah data primer dan data sekunder. Data primer diperoleh dari pengamatan langsung di lapangan, melalui wawancara dan melalui diskusi dengan beberapa narasumber yang berhubungan dengan produksi dan penjualan di CV XYZ yaitu kepala bagian penjualan, pemasaran, dan kepala produksi. Data sekunder diperoleh dari laporan keuangan, data penjualan tahun 2017-2018, data jumlah karyawan, data tingkat produksi di CV XYZ, BPS, serta sumber data lain yang terkait dengan penelitian ini.

Penelitian ini berfokus pada kegiatan analisis, formulasi, dan pengambilan keputusan atau kebijakan pada penentuan peramalan permintaan dan perencanaan produksi dalam jangka menengah CV XYZ yang harus dilakukan untuk mencapai proses bisnis yang lebih optimal dengan menggunakan analisis aggregate production planning (APP). Komposisi untuk penambahan input di perencanaan produksi yang diperhitungkan dalam penelitian ini meliputi hasil peramalan permintaan, jumlah jam kerja, jumlah unit inventory, jumlah unit subkontrak, jumlah unit yang di pasarkan. Tahapan yang diterapkan dalam melakukan analisis dan pengolahan data pada penelitian ini terdiri dari:

\section{Peramalan Permintaan}

Perencanaan agregat dimulai dengan peramalan permintaan untuk jangka menengah. Penerapan peramalan permintaan dapat membantu perusahaan untuk memperkirakan order yang akan diterima, sehingga jumlah produksi dapat diperkirakan dan ditentukan berdasarkan model peramalan terbaik. Analisis time series mempelajari pola gerakan nilainilai variabel pada satu interval waktu (mingguan/ bulanan/tahunan) yang teratur. Pemilihan model peramalan terbaik untuk $\mathrm{CV}$ XYZ dilakukan berdasarkan trial and error pada model peramalan moving average, exponential smoothing, holt's-winter dan autoregressive moving average (ARMA) dengan menggunakan software minitab. Peramalan dilakukan berdasarkan jumlah penjualan di CV XYZ pada bulan Januari 2017 sampai dengan Desember 2018.

\section{Menghitung kesalahan peramalan}

Mengukur seberapa baik suatu model peramalan atau membandingkan model tersebut dengan model lainnya dapat dilakukan dengan membandingkan data prediksi dengan data aktual. Tingkat akurasi peramalan dapat diukur dengan beberapa cara termasuk dari perhitungan yang umum digunakan adalah mean squared error (MSE) dengan mengukur kesalahan peramalan yang merupakan rata-rata selisih kuadrat antara nilai yang diramalkan dan diamati. MSE dapat dirumuskan:

$$
M S E=\frac{\sum\left(D_{t}-F_{t}\right)^{2}}{n-1}
$$

Keterangan: MSE (rata-rata selisih kuadrat); Dt (permintaan aktual); Ft (peramalan); $\mathrm{n}$ (jumlah periode).

\section{Perencanaan produksi agregat}

Setelah di dapatkan jumlah peramalan permintaan jangka menengah untuk periode 12 bulan kedepan. Perencanaan produksi dibuat untuk memenuhi jumlah permintaan tersebut dengan menyesuaikan jumlah produksi, pekerja, tingkat persediaan barang jadi ataupun kapasitas lainnya yang dapat memenuhi jumlah permintaan. Perencanaan produksi CV XYZ saat ini akan dibandingkan dengan strategi chase, Level, mixed untuk dapat menghasilkan strategi perencanaan produksi jangka menengah yang paling ideal. Strategi yang ideal akan menyeimbangkan jumlah persediaan dan permintaan yang ada serta mendapatkan total biaya produksi yang paling minimal.

Hasil penelitian ini diharapkan menghasilkan solusi yang dapat meningkatkan efektivitas dan efisiensi perusahaan pada umumnya dan produksi pada khususnya untuk mencapai market competitiveness yang lebih baik terutama dalam menghadapi perubahan situasi dan kondisi, dinamika bisnis, tantangan. Kerangka pemikiran dari penelitian ini dapat dilihat pada Gambar 2. 


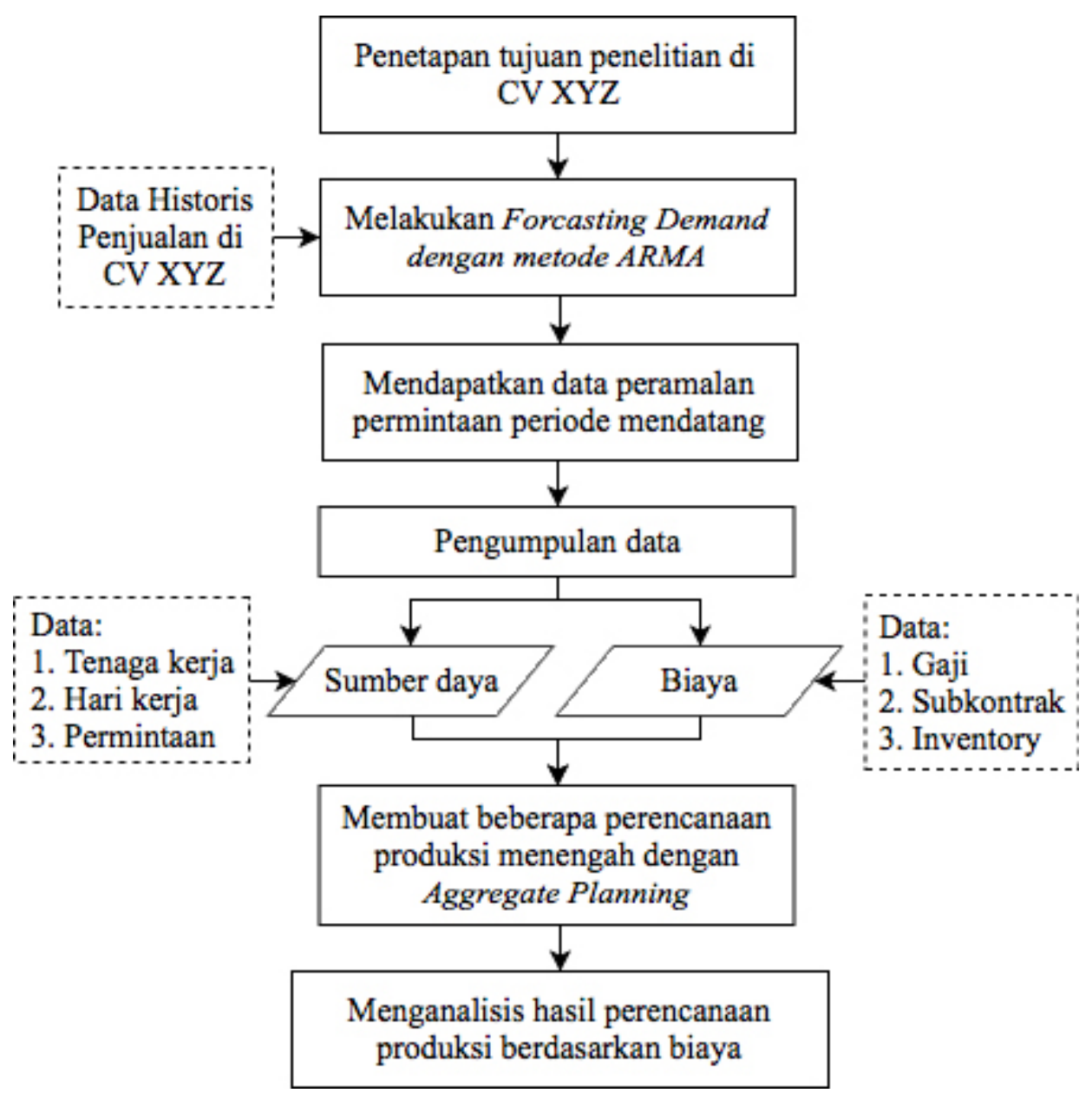

Gambar 2. Kerangka pemikiran penelitian

\section{HASIL}

\section{Peramalan Permintaan}

Peramalan merupakan alat bantu yang penting dalam perencanaan yang efektif dan efisien. Pengujian kestasioneran yang ada dalam data penjualan seperti Gambar 3 sangat diperlukan pada metode data time series. Peramalan dapat dilakukan apabila kondisi data sudah stasioner. Stasioneritas mempunyai makna bahwa tidak terdapat pertambahan serta penurunan pada alur data. Artinya, fluktuasi data berada di sekitar suatu nilai rata-rata yang konstan, tidak tergantung pada waktu dan varians dari fluktuasi tersebut. Kestasioneran data ini berkaitan dengan metode estimasi yang digunakan. Tidak stasionernya data akan mengakibatkan kurang baiknya model yang di estimasi.

Uji yang sangat sederhana untuk melihat kestasioneran data adalah dengan analisis grafik, yang dilakukan dengan membuat plot korelogram. Korelogram memberikan nilai Auto Correlation (AC) dan Partial Auto Correlation (PAC). Untukmenghitung autokorelasi dan autokorelasi parsial dapat digunakan program (software) komputer seperti MINITAB pada bagian time series. Penggunaan software MINITAB dalam menghasilkan $\mathrm{AC}$ dan PAC dalam grafik korelogram dapat membantu peneliti dalam mengidentifikasi model data time series yang terbentuk terutama identifikasi data stasioneritas atau non-stasioneritas seperti yang terlihat pada Gambar 4 dan Gambar 5.

Setelah dilakukan perhitungan peramalan dengan menggunakan lima metode perbandingan, dilakukan langkah untuk membandingkan hasil dari masingmasing metode ditinjau dari nilai MSE terendah. Hasil akhir dari perbandingan beberapa metode tersebut dapat diketahui dari Tabel 1.

Dari analisis yang telah dilakukan, dapat diketahui bahwa metode ARMA lebih tepat digunakan untuk menyelesaikan studi kasus perhitungan peramalan penjualan plywood di CV XYZ dengan nilai kesalahan MSE sebesar 0,020. Peramalan permintaan menggunakan metode ARMA menghasilkan grafik yang berfluktuasi menyerupai data historis penjualan 
perusahaan sebelumnya, seperti yang tertera pada Gambar 6. Grafik yang dihasilkan oleh software minitab dan memiliki nilai MSE sebesar 0,020, dengan tingkat kepercayaan sebesar $95 \%$, nilai tersebut merupakan nilai dengan angka kesalahan terkecil dibandingkan metode lainnya. Dengan grafik tersebut didapatkan hasil angka peramalan permintaan perusahaan akan untuk 12 bulan pada periode kedepan seperti yang terdapat pada Tabel 2. Angka peramalan permintaan tersebut masih dapat dijangkau oleh produksi perusahaan sehingga perusahaan tidak memerlukan kenaikan kapasitas produksi. Dengan rata-rata permintaan sebesar 2.880 $\mathrm{m}^{3}$, nilai permintaan tertinggi pada bulan Oktober 2019 sebesar $3.377 \mathrm{~m}^{3}$ dan permintaan terkecil pada bulan Jun-20, yaitu $2.018 \mathrm{~m}^{3}$.
Tabel 1. Perbandingan nilai MSE dari beberapa metode peramalan

\begin{tabular}{ll}
\hline Metode & MSE \\
\hline Moving Average (MA) & 0,066 \\
Single Exponential Smoothing (SES) & 0,052 \\
Double Exponential Smoothing (DES) & 0,065 \\
Holt-Winter's & 0,043 \\
Autoregressive Moving Average (ARMA) & 0,020 \\
\hline
\end{tabular}

Tabel 2. Hasil peramalan permintaan metode ARMA dalam 12 bulan

\begin{tabular}{lclc}
\hline Bulan & Permintaan & Bulan & Permintaan \\
\hline Jul-19 & 3.046 & Jan-20 & 3.102 \\
Aug-19 & 2.792 & Feb-20 & 2.634 \\
Sep-19 & 3.130 & Mar-20 & 2.859 \\
Oct-19 & 3.377 & Apr-20 & 3.104 \\
Nov-19 & 2.690 & May-20 & 2.548 \\
Dec-19 & 2.056 & Jun-20 & 2.018 \\
\hline
\end{tabular}

- Penjualan

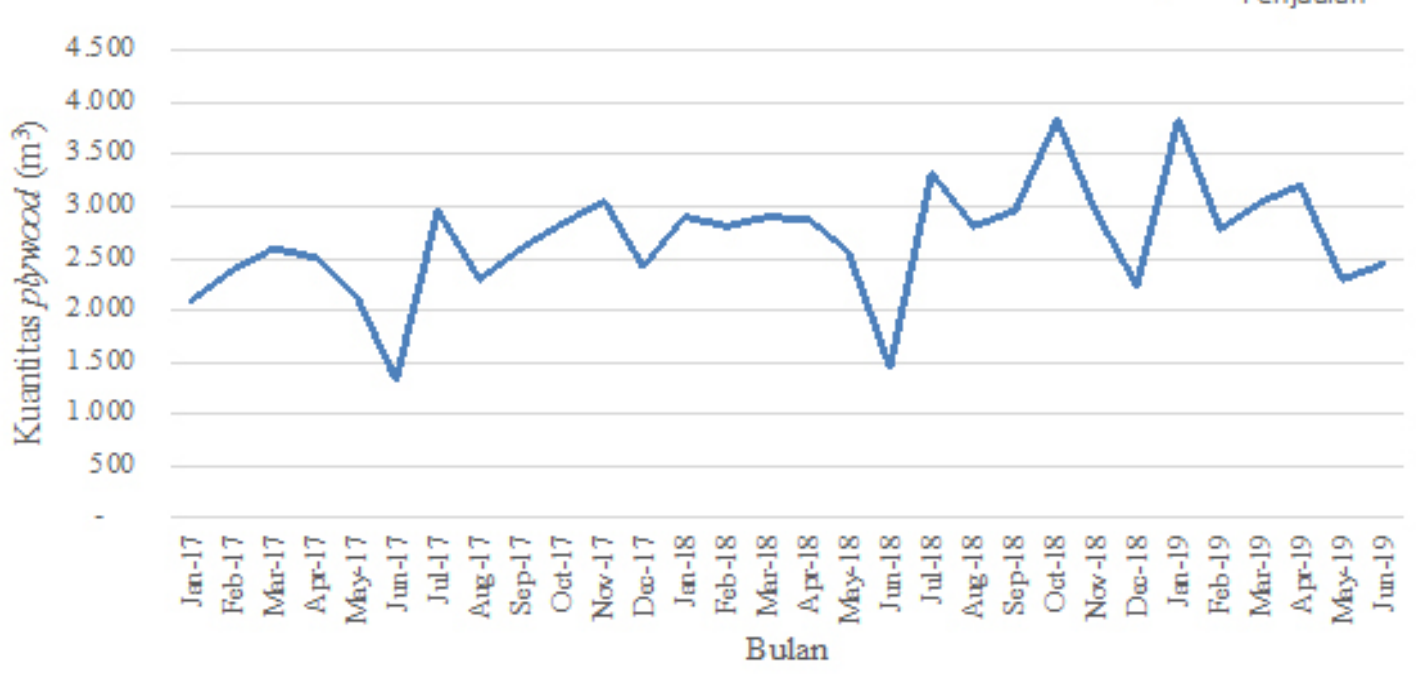

Gambar 3. Penjualan CV XYZ 2017-2019
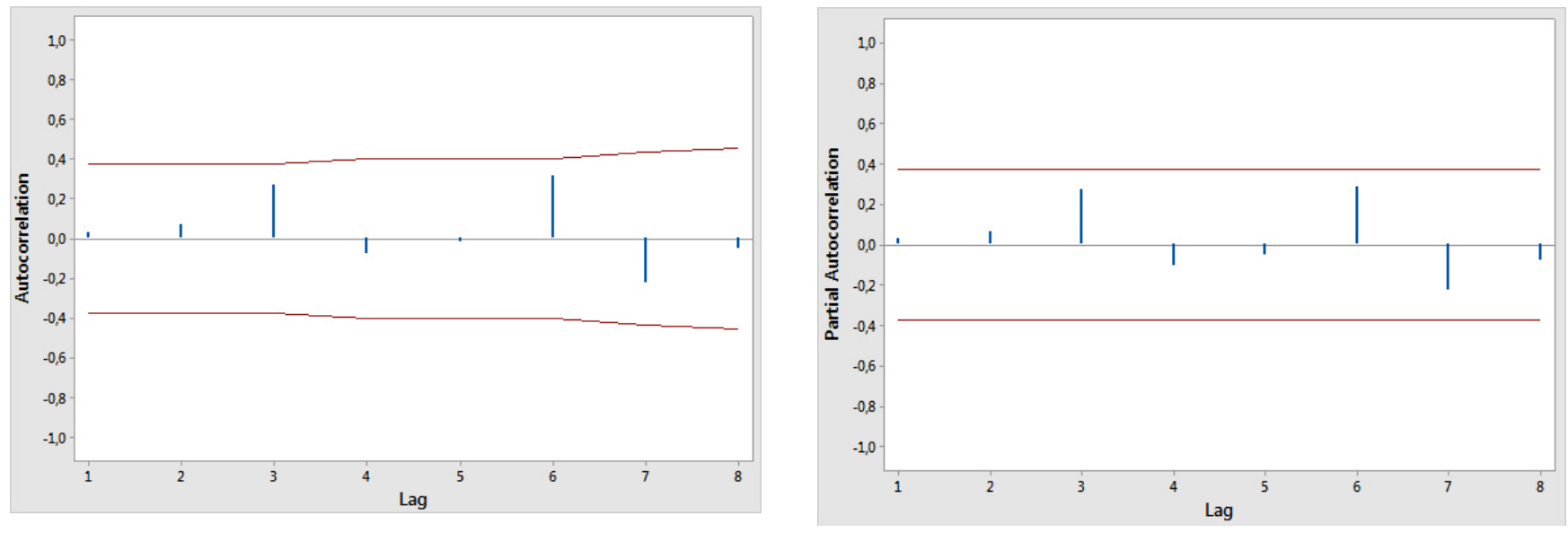

Gambar 4. Autocorelation 


\section{Perencanaan Produksi Agregat}

Perencanaan produksi agregat dihadapkan pada kendalakendala yang dikaitkan dengan kapasitas produksi, kebijakan perusahaan, jam kerja, serta permintaan konsumen. Kendala kapasitas kerja reguler adalah kendala yang berkaitan dengan waktu atau jam kerja normal yang tersedia untuk dipakai proses produksi, atau jumlah maksimum yang bisa diproduksi dalam bulanan. Jumlah jam kerja reguler per bulannya sesuai dengan hari kerja yang ada pada tiap bulannya yaitu 8 jam perhari, 40 jam perminggu. Hari kerja atau jam kerja yang berlaku dan dijadwalkan oleh perusahaan saat ini adalah 5,5 hari/minggu atau sejumlah 11 shift/ minggu, dengan jam kerja shift 1 yang berjalan pada jam 07.00 - 16.00 dan shift 2 yang berjalan pada jam 19.00 - 04.00 dan terdapat jam kerja lembur pada akhir shift selama 2 jam.

Operasi setiap perusahaan disebut efisien atau tidak, dapat didasarkan pada standart waktu produksi yang telah ditetapkan. Mengenai jumlah waktu yang harus digunakan untuk melaksanakan kegiatan tertentu dibawah kondisi kerja normal disebut dengan standar tenaga kerja (Handoko, 2015). Seperti yang tertera pada Tabel 3, standart produksi plywood yang dapat dihasilkan oleh perusahaan adalah $7.5 \mathrm{~m} 3 /$ jam dengan jumlah pekerja dalam 1 shiftnya sebanyak 300 orang. Saat ini, Terdapat 724 karyawan yang terdaftar sebagai pekerja. Subkontrak dilakukan dengan cara pembelian produk plywood pada perusahaan lain dan akan dilakukan finishing di CV XYZ. Pemasaran dilakukan dengan menurunan harga jual agar persediaan yang ada di gudang dapat lebih cepat terjual. Penjualan dilakukan di Indonesia dengan harga yang berbeda pada saat dijual eksport.

Pada Tabel 4 memperlihatkan perhitungan mengenai ketersediaan jumlah jam kerja yang dapat digunakan oleh perusahaan. Berdasarkan peraturan pemerintah mengenai pembatasan jam kerja karyawan yaitu 8 jam/hari dan 40 jam/minggu dengan jumlah karyawan sebanyak 724 orang. Ketersediaan hari kerja digunakan sebagai indikasi bila terjadi jumlah hari kerja pada salah perencanaan produksi yang melebihi ketersediaan hari kerja tersebut, maka hari kerja selanjutnya akan dihitung sebagai jam kerja lembur.

\section{Strategi CV XYZ}

Perencanaan produksi dengan strategi CV XYZ seperti yang tertera pada Tabel 5, dilakukan dengan cara menetapkan jumlah produksi mengikuti jumlah hari kerja yang dijadwalkan oleh perusahaan, yaitu 5,5 hari/minggu atau sejumlah 11 shift/minggu. Ratarata jumlah produksi plywood sebesar $2.710 \mathrm{~m}^{3} / \mathrm{bulan}$, jumlah rata-rata hari kerja perusahaan adalah 23 hari/ bulan dengan total hari kerja 271 hari/tahun. Jika terdapat kelebihan produksi akan disimpan ke gudang persediaan barang jadi yang akan menutupi kekurangan produksi pada bulan berikutnya. Namun, jika produksi kekurangan dan tidak dapat memenuhi permintaan, maka permintaan akan di bebankan ke produksi bulan berikutnya seperti pada bulan Mei 2020. Rata-rata sisa penjualan sebesar $700 \mathrm{~m}^{3} /$ bulan dengan biaya rata-rata Rp94.137.333/bulan.

\section{Strategi Level}

Perencanaan produksi dengan strategi level seperti yang tertera pada Tabel 6, dilakukan dengan cara menetapkan jumlah produksi mengikuti rata-rata total permintaan selama periode peramalan. Rata-rata jumlah produksi plywood sebesar $2.880 \mathrm{~m}^{3} /$ bulan. Jumlah ratarata hari kerja 23 hari/bulan dengan total hari kerja 278 hari/tahun. Kelebihan produksi akan disimpan ke gudang persediaan barang jadi yang akan menutupi kekurangan produksi pada bulan berikutnya. Rata-rata sisa penjualan berjumlah $959 \mathrm{~m}^{3} /$ bulan dengan biaya rata-rata $\mathrm{Rp} 129.044 .958 /$ bulan.

Tabel 3. Variabel yang berkaitan dengan strategi perencanaan produksi

\begin{tabular}{lc}
\hline \multicolumn{1}{c}{ Variabel produksi } & Jumlah \\
\hline Standart produksi & $7,5 \mathrm{~m}^{3} / \mathrm{jam}$ \\
Jumlah kebutuhan pekerja & $300 /$ shift \\
Jumlah pekerja terdaftar & 724 karyawan \\
Upah karyawan & $\mathrm{Rp} 8.410 / \mathrm{jam}$ \\
Upah lembur & $\mathrm{Rp} 14.584 / \mathrm{jam}$ \\
Biaya persediaan & $\mathrm{Rp} 134.562 / \mathrm{m}^{3}$ \\
Biaya subkontrak & $\mathrm{Rp} 411.339 / \mathrm{m}^{3}$ \\
Biaya pemasaran & $\mathrm{Rp} 133.269 / \mathrm{m}^{3}$ \\
\hline
\end{tabular}


Tabel 4.Perhitungan ketersediaan jam kerja

\begin{tabular}{ccccccc}
\hline Bulan & $\begin{array}{c}\text { Ketersediaan } \\
\text { Total Hari } \\
\text { Kerja (hari) }\end{array}$ & $\begin{array}{c}\text { Total Jam } \\
\text { Kerja per } \\
\text { Karyawan } \\
\text { (jam) }\end{array}$ & $\begin{array}{c}\text { Ketersediaan } \\
\text { Jam Kerja } \\
\text { dengan 724 } \\
\text { karyawan(jam) }\end{array}$ & $\begin{array}{c}\text { Ketersediaan } \\
\text { Jam Produksi } \\
\text { Perusahaan } \\
\text { (jam) }\end{array}$ & $\begin{array}{c}\text { Ketersediaan } \\
\text { Hari kerja } \\
\text { (hari) }\end{array}$ & $\begin{array}{c}\text { Jumlah } \\
\text { Produksi } \\
\text { Perusahaan } \\
\left(\mathrm{m}^{3}\right)\end{array}$ \\
\hline Jul-19 & 23 & 184 & 133.216 & 444 & 27,5 & 3.300 \\
Aug-19 & 22 & 176 & 127.424 & 424 & 26,5 & 3.180 \\
Sep-19 & 21 & 168 & 121.632 & 405 & 25 & 3.000 \\
Oct-19 & 23 & 184 & 133.216 & 444 & 27,5 & 3.300 \\
Nov-19 & 21 & 168 & 121.632 & 405 & 25 & 3.000 \\
Dec-19 & 22 & 176 & 127.424 & 424 & 26,5 & 3.180 \\
Jan-20 & 23 & 184 & 133.216 & 444 & 27,5 & 3.330 \\
Feb-20 & 20 & 160 & 115.840 & 386 & 24 & 2.880 \\
Mar-20 & 22 & 176 & 127.424 & 424 & 26,5 & 3.180 \\
Apr-20 & 22 & 176 & 127.424 & 424 & 26,5 & 3.180 \\
May-20 & 21 & 168 & 121.632 & 405 & 25 & 3.000 \\
Jun-20 & 22 & 176 & 127.424 & 424 & 26,5 & 3.180 \\
\hline
\end{tabular}

Tabel 5. strategi produksi saat ini di CV XYZ

\begin{tabular}{|c|c|c|c|c|c|c|c|}
\hline Bulan & Satuan & Jul-19 & Aug-19 & Sep-19 & Oct-19 & Nov-19 & Dec-19 \\
\hline Persediaan & $\mathrm{m}^{3}$ & 1.145 & 1.099 & 1.188 & 819 & 443 & 513 \\
\hline Hari Kerja & hari & 25 & 24 & 23 & 25 & 23 & 22 \\
\hline Produksi & $\mathrm{m}^{3}$ & 3.000 & 2.880 & 2.760 & 3.000 & 2.760 & 2.640 \\
\hline Permintaan & $\mathrm{m}^{3}$ & 3.046 & 2.791 & 3.129 & 3.376 & 2.690 & 2.056 \\
\hline Sisa Penjualan & $\mathrm{m}^{3}$ & 1.099 & 1.188 & 819 & 443 & 513 & 1.097 \\
\hline Biaya Persediaan & $\mathrm{Rp}$ & 147.883 .638 & 159.859 .656 & 110.206 .278 & 59.610 .966 & 69.030 .306 & 147.614 .514 \\
\hline Biaya Gaji & $\mathrm{Rp}$ & 1.009 .200 .000 & 968.832 .000 & 928.464 .000 & 1.009 .200 .000 & 928.464 .000 & 888.096 .000 \\
\hline Biaya Total & $\mathrm{Rp}$ & 1.157 .083 .638 & 1.128 .691 .656 & 1.038 .670 .278 & 1.068 .810 .966 & 997.494 .306 & 1.035 .710 .514 \\
\hline Bulan & Satuan & Jan-20 & Feb-20 & Mar-20 & Apr-20 & May-20 & Jun-20 \\
\hline Persediaan & $\mathrm{m}^{3}$ & 1.097 & 815 & 882 & 784 & 440 & -427 \\
\hline Hari Kerja & hari & 23.5 & 22.5 & 23 & 23 & 14 & 23 \\
\hline Produksi & $\mathrm{m}^{3}$ & 2.820 & 2.700 & 2.760 & 2.760 & 1.680 & 2.760 \\
\hline Permintaan & $\mathrm{m}^{3}$ & 3.102 & 2.633 & 2.858 & 3.104 & 2.547 & 2.018 \\
\hline Sisa Penjualan & $\mathrm{m}^{3}$ & 815 & 882 & 784 & 440 & -427 & 315 \\
\hline Biaya Persediaan & $\mathrm{Rp}$ & 109.668 .030 & 118.683 .684 & 105.496 .608 & 59.207 .280 & 0 & 42.387 .030 \\
\hline Biaya Gaji & $\mathrm{Rp}$ & 948.648 .000 & 908.280 .000 & 9284.64 .000 & 928.464 .000 & 565.152 .000 & 928.464 .000 \\
\hline Biaya Total & $\mathrm{Rp}$ & 1.058 .316 .030 & 1.026 .963 .684 & 1.033 .960 .608 & 987.671 .280 & 565.152 .000 & 970.851 .030 \\
\hline Total Biaya (Rp) & & & & & & \multicolumn{2}{|c|}{12.069 .538 .590} \\
\hline Rata-Rata Biaya P & - Bulan (F & & & & & \multicolumn{2}{|c|}{1.005 .794 .883} \\
\hline
\end{tabular}


Tabel.6..Perhitungan.strategi.level.periode.12.bulan

\begin{tabular}{|c|c|c|c|c|c|c|c|}
\hline Bulan & Satuan & Jul-19 & Aug-19 & Sep-19 & Oct-19 & Nov-19 & Dec-19 \\
\hline Persediaan & $\mathrm{m}^{3}$ & 1.145 & 979 & 1.068 & 819 & 323 & 513 \\
\hline Hari.Kerja & hari & 24 & 24 & 24 & 24 & 24 & 24 \\
\hline Produksi & $\mathrm{m}^{3}$ & 2.880 & 2.880 & 2.880 & 2.880 & 2.880 & 2.880 \\
\hline Permintaan & $\mathrm{m}^{3}$ & 3.046 & 2.791 & 3.129 & 3.376 & 2.690 & 2.056 \\
\hline Sisa.Penjualan & $\mathrm{m}^{3}$ & 979 & 1.068 & 819 & 323 & 513 & 1.337 \\
\hline Biaya.Persediaan & $\mathrm{Rp}$ & 131.736 .198 & 143.712 .216 & 110.206 .278 & 43.463 .526 & 69.030 .306 & 179.909 .394 \\
\hline Biaya Gaji & $\mathrm{Rp}$ & 968.832 .000 & 968.832 .000 & 968.832 .000 & 968.832 .000 & 968.832 .000 & 968.832 .000 \\
\hline Biaya Total & $\mathrm{Rp}$ & 1.100 .568 .198 & 1.112 .544 .216 & 1.079 .038 .278 & 1.012 .295 .526 & 1.037 .862 .306 & 1.148 .741 .394 \\
\hline Bulan & Satuan & Jan-20 & Feb-20 & Mar-20 & Apr-20 & May-20 & Jun-20 \\
\hline Persediaan & $\mathrm{m}^{3}$ & 1.337 & 1.115 & 1.362 & 1.384 & 1.160 & 293 \\
\hline Hari.Kerja & hari & 24 & 24 & 24 & 24 & 14 & 24 \\
\hline Produksi & $\mathrm{m}^{3}$ & 2.880 & 2.880 & 2.880 & 2.880 & 1.680 & 2.880 \\
\hline Permintaan & $\mathrm{m}^{3}$ & 3.102 & 2.633 & 2.858 & 3.104 & 2.547 & 2.018 \\
\hline Sisa.Penjualan & $\mathrm{m}^{3}$ & 1.115 & 1.362 & 1.384 & 1.160 & 293 & 1.155 \\
\hline Biaya.Persediaan & $\mathrm{Rp}$ & 150.036 .630 & 183.273 .444 & 186.233 .808 & 156.091 .920 & 39.426 .666 & 155.419 .110 \\
\hline Biaya.Gaji & $\mathrm{Rp}$ & 968.832 .000 & 968.832 .000 & 968.832 .000 & 968.832 .000 & 565.152 .000 & 968.832 .000 \\
\hline Biaya.Total & $\mathrm{Rp}$ & 1.118 .868 .630 & 1.152 .105 .444 & 1.155 .065 .808 & 1.124 .923 .920 & 604.578 .666 & 1.124 .251 .110 \\
\hline Total.Biaya.(Rp) & & & & & & \multicolumn{2}{|c|}{12.770 .843 .496} \\
\hline Rata-Rata.Biaya.P & r.Bulan.( & Rp) & & & & \multicolumn{2}{|c|}{1.064 .236 .958} \\
\hline
\end{tabular}

\section{Strategi Chase}

Perencanaan produksi dengan strategi chase seperti yang tertera pada Tabel 7, dilakukan dengan cara menetapkan jumlah produksi mengikuti jumlah peramalan permintaan yang ada pada tiap bulannya. Jumlah produksi akan di seimbangkan dengan hari kerja dengan pembulatan kebawah. Rata-rata jumlah produksi plywood sebesar $2.570 \mathrm{~m}^{3} /$ bulan, jumlah rata-rata hari kerja adalah 21,5 hari/bulan dengan total hari kerja 257 hari/tahun. Kekurangan yang ada pada produksi dikarenakan pembulatan hari kerja ditutupi oleh jam kerja lembur perusahaan. Rata-rata produksi pada jam lembur adalah $114 \mathrm{~m}^{3} /$ bulan dengan biaya rata-rata Rp66.357.200/bulan.

\section{Strategi mixed}

Perencanaan produksi dengan strategi mixed seperti pada Tabel 8, dilakukan dengan cara menetapkan jumlah produksi mengikuti jumlah maksimum ketersediaan hari kerja yang dimiliki oleh perusahaan. Rata-rata jumlah produksi plywood sebesar $3.030 \mathrm{~m}^{3 /}$ bulan. Jumlah rata-rata hari kerja adalah 25,5 hari/ bulan dengan total hari kerja 303 hari/tahun. Kelebihan produksi akan dijual dengan melakukan potongan harga sesuai dengan biaya pemasaran. Kekurangan produksi akan ditutupi dengan produksi di jam lembur seperti yang ada pada bulan September 2019 dan Mei 2020. Rata-rata produksi pada saat lembur adalah 89,5 $\mathrm{m}^{3} /$ bulan dengan biaya rata-rata Rp52.113.493/bulan. Rata-rata jumlah plywood yang dipasarkan adalah 436 $\mathrm{m}^{3} /$ bulan dengan biaya rata-rata Rp58.050.190/bulan.

\section{Perbandingan Strategi}

Berdasarkan perbandingan strategi perencanaan produksi yang dapat dilihat pada Tabel 9, strategi chase merupakan strategi yang dapat dijadikan acuan perencanaan produksi untuk 12 bulan kedepan, disebabkan biaya produksi yang dihasilkan paling rendah diantara strategi lainnya, yaitu Rp11.170.862 400. Dengan rata-rata biaya perbulannya sebesar Rp930.905.200. Strategi terbaik kedua yaitu strategi mixed yang mempunyai rata-rata biaya perbulan Rp1.129.455.684 dengan ramalan penjualan sebesar $38.577 \mathrm{~m}^{3}$. Biaya rata-rata kedua strategi jika dihitung per $\mathrm{m}^{3}$ maka didapatkan biaya masing-masing sebesar Rp334.958 dan Rp351.335. Sedangkan biaya rata-rata strategi CV XYZ dan strategi level jika dihitung per $\mathrm{m}^{3}$ adalah Rp361.900 dan Rp382.933. 
Tabel 7. Perhitungan strategi chase periode 12 bulan

\begin{tabular}{|c|c|c|c|c|c|c|c|}
\hline Bulan & Satuan & Jul-19 & Aug-19 & Sep-19 & Oct-19 & Nov-19 & Dec-19 \\
\hline Persediaan & $\mathrm{m}^{3}$ & 1.145 & 0 & 0 & 0 & 0 & 0 \\
\hline Hari Kerja & hari & 16 & 23 & 26 & 27,5 & 22 & 16,5 \\
\hline Produksi & $\mathrm{m}^{3}$ & 1.860 & 2.760 & 3.120 & 3.300 & 2.640 & 1.980 \\
\hline Permintaan & $\mathrm{m}^{3}$ & 3.046 & 2.791 & 3.129 & 3.376 & 2.690 & 2.056 \\
\hline Lembur & $\mathrm{m}^{3}$ & 41 & 31 & 9 & 76 & 50 & 76 \\
\hline Sisa Penjualan & $\mathrm{m}^{3}$ & 0 & 0 & 0 & 0 & 0 & 0 \\
\hline Biaya Lembur & $\mathrm{Rp}$ & 23.917 .760 & 18.084 .160 & 5.250 .240 & 44.335 .360 & 29.168 .000 & 44.335 .360 \\
\hline Biaya Gaji & $\mathrm{Rp}$ & 625.704 .000 & 928.464 .000 & 1.049 .568 .000 & 1.110 .120 .000 & 888.096 .000 & 666.072 .000 \\
\hline Total Biaya & $\mathrm{Rp}$ & 649.621 .760 & 946.548 .160 & 1.054 .818 .240 & 1.154 .455 .360 & 917.264 .000 & 710.407 .360 \\
\hline & & Jan-20 & Feb-20 & Mar-20 & Apr-20 & May-20 & Jun-20 \\
\hline Persediaan & $\mathrm{m}^{3}$ & 0 & 0 & 0 & 0 & 0 & 0 \\
\hline Hari Kerja & hari & 25,5 & 21,5 & 23,5 & 25,5 & 14 & 16,5 \\
\hline Produksi & $\mathrm{m}^{3}$ & 3.060 & 2.580 & 2.820 & 3.060 & 1.680 & 1.980 \\
\hline Permintaan & $\mathrm{m}^{3}$ & 3.102 & 2.633 & 2.858 & 3.104 & 2.547 & 2.018 \\
\hline Lembur & $\mathrm{m}^{3}$ & 42 & 53 & 38 & 44 & 867 & 38 \\
\hline Sisa Penjualan & $\mathrm{m}^{3}$ & 0 & 0 & 0 & 0 & 0 & 0 \\
\hline Biaya Lembur & $\mathrm{Rp}$ & 24.501 .120 & 30.918 .080 & 22.167 .680 & 25.667 .840 & 505.773 .120 & 22.167 .680 \\
\hline Biaya Gaji & $\mathrm{Rp}$ & 1.029 .384 .000 & 867.912 .000 & 948.648 .000 & 1.029 .384 .000 & 565.152 .000 & 666.072 .000 \\
\hline Total Biaya & $\mathrm{Rp}$ & 1.053 .885 .120 & 898.830 .080 & 970.815 .680 & 1.055 .051 .840 & 1.070 .925 .120 & 688.239 .680 \\
\hline Total Biaya (Rp) & & & & & & \multicolumn{2}{|c|}{11170862400} \\
\hline Rata-Rata Biaya I & r Bulan (I & & & & & \multicolumn{2}{|c|}{930905200} \\
\hline
\end{tabular}

Tabel 8. Perhitungan strategi mixed periode 12 bulan

\begin{tabular}{|c|c|c|c|c|c|c|c|}
\hline Bulan & Satuan & Jul-19 & Aug-19 & Sep-19 & Oct-19 & Nov-19 & Dec-19 \\
\hline Persediaan & $\mathrm{m}^{3}$ & 1.145 & 0 & 0 & 0 & 0 & 0 \\
\hline Hari Kerja & hari & 27,5 & 26,5 & 25 & 27,5 & 25 & 26,5 \\
\hline Produksi & $\mathrm{m}^{3}$ & 3.300 & 3.180 & 3.000 & 3.300 & 3.000 & 3.180 \\
\hline Permintaan & $\mathrm{m}^{3}$ & 3.046 & 2.791 & 3.129 & 3.376 & 2.690 & 2.056 \\
\hline Pemasaran & $\mathrm{m}^{3}$ & 1.399 & 389 & 0 & 0 & 310 & 1.124 \\
\hline Lembur & $\mathrm{m}^{3}$ & 0 & 0 & 129 & 76 & 0 & 0 \\
\hline Sisa Penjualan & $\mathrm{m}^{3}$ & 0 & 0 & 0 & 0 & 0 & 0 \\
\hline Biaya Pemasaran & $\mathrm{Rp}$ & 186.444 .730 & 51.842 .030 & 0 & 0 & 41.313 .700 & 149.795 .480 \\
\hline Biaya Lembur & $\mathrm{Rp}$ & 0 & 0 & 75.253 .440 & 44.335 .360 & 0 & 0 \\
\hline Biaya Gaji & $\mathrm{Rp}$ & 1.110 .120 .000 & 1.069 .752 .000 & 1.009 .200 .000 & 1.110 .120 .000 & 1.009 .200 .000 & 1.069 .752 .000 \\
\hline Total Biaya & $\mathrm{Rp}$ & 1.296 .564 .730 & 1.121 .594 .030 & 1.084 .453 .440 & 1.154 .455 .360 & 1.050 .513 .700 & 1.219 .547 .480 \\
\hline & & Jan-20 & Feb-20 & Mar-20 & Apr-20 & May-20 & Jun-20 \\
\hline Persediaan & $\mathrm{m}^{3}$ & 0 & 0 & 0 & 0 & 0 & 0 \\
\hline Hari Kerja & hari & 27,5 & 24 & 26,5 & 26,5 & 14 & 26,5 \\
\hline Produksi & $\mathrm{m}^{3}$ & 3.300 & 2.880 & 3.180 & 3.180 & 1.680 & 3.180 \\
\hline Permintaan & $\mathrm{m}^{3}$ & 3.102 & 2.633 & 2.858 & 3.104 & 2.547 & 2.018 \\
\hline Pemasaran & $\mathrm{m}^{3}$ & 198 & 247 & 322 & 76 & 0 & 1.162 \\
\hline Lembur & $\mathrm{m}^{3}$ & 0 & 0 & 0 & 0 & 867 & 0 \\
\hline Sisa Penjualan & $\mathrm{m}^{3}$ & 0 & 0 & 0 & 0 & 0 & 0 \\
\hline Biaya Pemasaran & $\mathrm{Rp}$ & 26.387 .460 & 32.917 .690 & 42.912 .802 & 10.128 .487 & 0 & 1.54 .859 .240 \\
\hline Biaya Lembur & $\mathrm{Rp}$ & 0 & 0 & 0 & 0 & 505.773 .120 & 0 \\
\hline Biaya Gaji & $\mathrm{Rp}$ & 1.110 .120 .000 & 968.832 .000 & 1.069 .767 .900 & 1.069 .767 .900 & 565.160 .400 & 1.069 .767 .900 \\
\hline Total Biaya & $\mathrm{Rp}$ & 1.136 .507 .460 & 1.001 .749 .690 & 1.112 .680 .702 & 1.079 .896 .387 & 1.070 .933 .520 & 1.224 .627 .140 \\
\hline Total Biaya (Rp) & & & & & & \multicolumn{2}{|c|}{13.553 .523 .639} \\
\hline \multicolumn{6}{|c|}{ Rata-Rata Biaya Per Bulan (Rp) } & \multicolumn{2}{|c|}{1.129 .460 .303} \\
\hline
\end{tabular}




\section{Implikasi Manjerial}

Perencanaan produksi yang efektif membutuhkan informasi yang baik. Sumber daya yang tersedia selama periode perencanaan harus diketahui dan ramalan terhadap permintaan yang diperkirakan harus tersedia. Perencanaan harus mempertimbangkan kebijakan mengenai jumlah hari kerja yang didapat oleh masing-masing pekerja. Jika perusahaan tetap menginginkan pekerja dengan jumlah 724 karyawan, perusahaan dapat mengambil strategi mixed. Biaya yang dikeluarkan dengan strategi mixed akan lebih banyak dibandingkan strategi lainnya, namun plywood yang terjual akan lebih banyak dikarenakan adanya strategi menarik permintaan. Sisa penjualan plywood di pasar ekspor yang berada di gudang persediaan akan dijual ke beberapa toko bangunan atau material dengan potongan harga yang sudah disepakati oleh perusahaan masuk kedalam biaya pemasaran.

\section{KESIMPULAN DAN SARAN}

\section{Kesimpulan}

Dari hasil penelitian diketahui bahwa strategi perencanaan produksi agregat menghasilkan keseimbangan antara persediaan dan permintaan perusahaan untuk periode kedepan serta mendapatkan perhitungan biaya produksi. Pada hasil perbandingan strategi perencanaan produksi agregat, ditemukan strategi dengan biaya rata-rata per bulan yang paling rendah. Biaya tersebut dihasilkan menggunakan strategi chase dengan jumlah penjualan produk sebanyak $33.350 \mathrm{~m}^{3}$. Strategi chase menggunaan pilihan variabel strategi dengan cara mengikuti jumlah permintaan tiap bulannya dengan menambah dan mengurangi jumlah jam kerja perusahaan supaya jumlah produksi bisa berimbang atau sama dengan jumlah permintaan pada bulan tersebut. Penggunaan strategi chase juga berdampak pada dampak penurunan biaya produksi sebesar $43 \%$, dibandingkan dengan rata-rata biaya produksiperusahaan pada tahun 2017-2018yaitu sebesar Rp1.633.316.531, dengan menggunakan strategi chase biaya produksi perbulan menjadi Rp930.905.200.

\section{Saran}

Perencanaan produksi yang telah dirumuskan sangat bergantung kepada penjadwalan dan pembagian jam kerja yang ada di perusahaan. Perusahaan disarankan untuk bisa lebih fokus pada penjadwalan jam kerja dan merincinya secara mendetail, konsisten melaksanakan dan mengevaluasi secara terus menerus pada peramalan permintaan dan perencanaan produksi. Jumlah pekerja yang dibutuhkan berdasarkan produksi dan ketersediaan jam kerja bagi karyawan untuk setiap bulan perlu lebih diperhatikan. Hal tersebut berdampak pada efisiensi tenaga kerja dan efisiensi jam lembur. Untuk dapat merancang penjadwalan jam kerja yang sesuai dengan perencanaan produksi yang ada, maka penelitian lebih lanjut dapat dilakukan dengan menganalisis master production schedule (MPS) untuk perencanaan produksi jangka pendek, serta juga dapat menganalisis business plan untuk perencanaan produksi jangka panjang dengan mengacu pada perencanaan produksi agregat.

\section{DAFTAR PUSTAKA}

Amri, Trisna, Harahap EN. 2012. Perencanaan pengendalian produksi air minum dalam kemasan menggunakan metode aggregate planning. Malikussaleh Industrial Engineering Journal 1(1): 11-18.

BPS. 2018. Ekspor kayu lapis menurut negara tujuan utama. https://www.bps.go.id/ statictable/2014/09/08/1022/ekspor-kayu-lapismenurut-negara-tujuan-utama-2000-2015.html. [5 Feb 2019].

Fajar M, Lestari YD. 2017. Aggregate planning analysis in PT Akebono Brake Astra Indonesia. Journal of Business and Management 6(2): 182-191.

Filho OS, Cezarino W, Ratto J. 2010. Aggregate production planning: modeling solution via excel spreadsheet and solver. IFAC 8(10): 89-94.

Gansterer M. 2015. Aggregate planning and forecasting in make-to-order production systems. International Journal of Production Economics 170(1): 521-528.

Handoko TH. 2015. Dasar-dasar Manajemen Produksi dan Operasi. Yogyakarta: BPFE-Yogyakarta.

Kemenperin. 2018. Kementrian Perindustrian Republik Indonesia. https://kemenperin.go.id/direktori-ek sportir? what $=$ plywood $\&$ prov $=0 \&$ hal $=6 . \quad[5$ Feb 2019].

Kementrian Perdagangan Republik Indonesia. 2017. Statistik: 10 komoditi utama dan potensial. http:// www.kemendag.go.id/id/economic-profile/10main-and-potential-commodities. [5 Feb 2019].

Longdong FM. 2016. Penerapan taget costing dalam 
perencanaan biaya produksi pada CV Sinar mandiri. Jurnal EMBA. 4(1): 1409-1418.

Noegraheni E, Nuradli H. 2016. Aggregate planning to minimize cost of production in manufacturing company. Binus Business Review. 7(1): 39-45.

Olhager J, Wikner J. 2000. Production planning and control Tools. International Journal of Production Research. 51(23): 210-220.

Purnomo A. 2010. Perencanaan produksi dan pengendalian persediaan bahan baku pada pengrajin tahu dan tempe Cibogo Bandung. Jurnal Teknik Industri UNPAS. 1(1): 67-88.

Rahmadani A, Rahman A, Tantrika CF. 2012. Perencanaan agregate chase strategy dengan analisis kebutuhan operator dan sesuai fluktuasi permintaan rokok (Studi kasus: PR. Adi Bungsu, Malang). Jurnal Rekayasa dan Manajemen Sistem Industri. 2(6): 1192-1202.
Sobandi KA, Kosasih S. 2014. Manajemen Operasi. Ed ke-2. Jakarta: Mitra Wacana Media.

Susanti L, Machfud, Hasbullah R. 2015. Pengendalian persediaan bahan baku base material pada industri keramik di PT.XYZ. Jurnal Aplikasi Bisnis dan Manajemen 1(2): 108-117.

Susanto NN, Chaeron M, Sutrisno. 2017. Penentuan harga produk plywood menggunakan metode activity based costing system. Jurnal OPSI 10(2): 1693-2102.

Tridge. 2016. Export: Plywood. https://www.tridge. com/intelligences/plywood/export. $\quad\left[\begin{array}{ll}5 & \text { Feb }\end{array}\right.$ 2019].

Wardhani AR. 2010. Perencanaan agregat dengan metode transportasi pada PT X Pasuruan. Widya Teknika 18(1): 6-10. 